Lecturer: ASS. Prof. Dr. S M Abdul Qudus

Subject: Globalisation and Governance

\title{
The Impact of Record Management on Public Procurement Performance in Kampala Capital City Authority.
}

\author{
Kajoba Abdul Rahim Abdallah \\ Kajoba2018@gmail.com \\ Matric Number: G1917131 \\ Masters of Human Science in Political Science. \\ International Islamic University Malaysia
}

\begin{abstract}
Public Reform and Development Secretariat (GoK, 2005) reports indicates that corruption and discretionary powers contribute to the poor delivery of services in government apparatuses and departments. The loss of control of records has consequences for all citizens, especially for the poorest who are least able to defend themselves. Relevant and accurate public records are essential to preserving the rule of law and demonstrating fair, equal, and consistent treatment of citizens. All citizens are entitled to access to records and information yet in most cases, they do not get them or if they do, it takes a long time because of inadequate information systems, lack of appropriate use of technology as well as challenges to do with the human resources establishment and functions. By using an internet data search on government reports ,books, journalS, articles, and websites Paper is going to investigate on the effect of record management on public procurement performance in Kampala Capital City Authority.
\end{abstract}

Key words: Decentralization, Record Keeping, Service Delivery, Kampala Capital City Authority. 


\section{Background}

Records management originated from the US federal government during the late 1940s, evolving from the USA archival profession (Langemo, 2002). The US national archive was established in 1934 to handle the past accumulation of federal documentation and the increasing volumes of records generated by the US federal government. In response to this growth, President Harry S. Truman established the commission on the organization of the executive branch of the government, which became known as the Hoover Commission in the late 1940s. A task force on paperwork management was established and Emmett J. Leahy was selected as chairman. In 1940s, the Hoover Commission came up with the term records management (Langemo, 2002). It is important to note that this is the first time this term is used and prior to this, what we knew as records management was referred to as paperwork.

Over the past few years, developing countries have been awakened on the importance of effective record management of the public procurement process at both central and local government levels, and its subsequent contribution to improved governance of the public sector (Basheka, 2008). Procurement as a function that was traditionally viewed as a clerical and reactive task has since positioned itself among core organizational functions, and its management is becoming increasingly critical for the well-functioning of any organization (Basheka, 2008). Procurement is becoming important at the local level, in parallel with decentralization and the increasing range of functions performed by local governments in most countries (Schiavo-Campo and Sundaram, 2000).

In Africa, lack of awareness of modern records management is widespread in many public and private sector organizations. There are inadequate policies, standards and guidelines, as well as inefficiency and lack of management continuity (Wamukoya and Mutula, 2005). In addition to this, findings from a baseline study by Lam and Wong (2011) indicated that poor records management affected procurement performance, especially in contract management and disposal process areas. This is a good development for the public procurement system in Africa, as procurement planning is a critical component for the realization of public procurement objectives. Procurement records are critical in promoting the principles of transparency and accountability, and weaknesses in this area have implications for the efficiency and effectiveness of the public procurement system (Chachage and Ngulube, 2006).

In Uganda, given the current poor state of records management, the government has taken a number of steps to support records management and archives in the country. These include the following among others: Circular No. 2 of 1976 was about the need for all government departments to manage and store records, and this was fully implemented in 1988.

In 1990, the Department of Records and Information Management was created in the Ministry of Public Service and in 1994, the department was moved from the office of the President to the Ministry of Public Service (Nyamungu, 2010). Uganda did not have a law relating directly to records until 2001, when the National Records and Archives Act (2001) were created. According to this Act, all records with historical, administrative, legal, fiscal, informative, research and educational value must be deposited with the national archives, and according to Uganda's The 
Local Governments Act (1997 as amended), for purposes of accountability, the Ministry of Local Government expects all councils to keep records of activities and transactions; the Act further requires that councils keep proper books of accounts and other related records.

However, despite the presence of these acts, Uganda still has weak laws and inactive legislative provisions to promote good records and archives management, and not much effort has been made to engage legal and policymakers on the need and value of functional legal and policy provisions for records and archives management (Okello, 2008). Therefore, this study addresses the influence of records management on procurement performance.

KACC (2006) and the Public Reform and Development Secretariat (GoK, 2005) reports indicates that corruption and discretionary powers contribute to the poor delivery of services in Government Departments. The loss of control of records has consequences for all citizens, especially for the poorest who are least able to defend themselves. Relevant and accurate public records are essential to preserving the rule of law and demonstrating fair, equal, and consistent treatment of citizens. All citizens are entitled to access to records and information yet in most cases, they do not get them or if they do, it takes a long time because of inadequate information systems, lack of appropriate use of technology as well as challenges to do with the human resources establishment and functions.

All aspects of public service, including health, education, pensions, land, and judicial rights, depend upon well-kept and well-managed records. Records are vital to virtually every aspect of the governance process. The effectiveness and efficiency of the public service across the range of Government functions depends upon the availability of and access to information held in records. Records when well managed enhances storage, access and retrieval, while at the same time mitigates the dangers of damage, loss, theft, traffic delay leading to missing targets among others should be clear (GoK, 2012).

Badly managed records adversely affect the broad scope of public service reforms, and development projects are often difficult to implement and sustain effectively in the absence of well managed records. (http://www.irmt.org on 19th March, 2013)

The Anti - Corruption Agency, KACC, (2006) conducted an audit of the Immigration Department's systems, policies, procedures and practices and highlighted that the employees charged with records management, at the time, had no formal training in the field. Most of the records systems in the Department are manual compounded by the recent decision to decentralize the operations of the Department in other parts of the country. To this end, corroborating the public records created in the satellite stations has continued to trouble the strategic thinking in the Department. The study sought to investigate the impact of records management reforms on the delivery of services at the Department of Immigration of Kenya since 2006.

\section{The influence of records creation on public procurement performance.}

Records creation is where information is initially created or obtained for purposes of evidence of official business (National Archives of Canada, 2003). In this particular study, records creation has been categorized as recording, referencing, classification and indexing. "Effective records creation is said to have a positive effect on the performance of the procurement function" (ISO 15489, 2001; Kenya Public Procurement Oversight Authority, 2008). 
In the same perspective, World Bank (2010) indicates that record-keeping is a fundamental activity of public administration that without records there can be no rule of law and no accountability. This signifies that procurement records play a significant role as evidence of purchases of goods and services. Therefore, poorly managed records mean that an organization does not have ready access to authoritative information to support sound decision-making and delivery of programs and services. This contributes to difficulties in retrieval and efficient use of procurement records, which affects the audit process.

Linked to the above, Damulira (2013) argues that without access to records, the public does not have the evidence needed to hold officials accountable or to insist on the prosecution of corruption and fraud, which directly affects procurement performance. Damulira (2013) further argues that badly managed records adversely affect the broad scope of public service reforms, and development projects are often difficult to implement and sustain effectively in the absence of well-managed records. The researcher concurs with the above facts that records are required for the past, present and future events. Therefore, in this study, it is anticipated that records creation has an influence on procurement performance.

The management of records creation supports complex decision-making processes within organizations (Duranti, 2010; Mnjama and Wamukoya, 2007). In Uganda, it is a requirement that procurement transactions are properly authorized and fully supported by written records. According to the Public Procurement and Disposal of Assets (PPDA) Act (2003), Part V, Section (1)1), Public Procuring and Disposing Entities (PDEs) should maintain detailed records of all their proceedings. PPDA Act (2003) is the law that regulates public sector procurement in Uganda, whereas the PPDA authority is the body that is mandated to oversee public sector procurement. According to the PPDA Act, procurement departments are called Procuring and Disposing Units (PDUs), whereas government self-accounting organizations are referred to as PDEs.

Informational values derive, as is evident from the very term, from the information that is in public records on the matters with which public agencies deal; not from the information that is in such records on the public agencies themselves. The greater proportion of modern public records preserved in an archival institution are valued less for the evidence they contain of Government action than for the information they contain about particular persons, situations, events, conditions, problems, materials, and properties in relation to which the question of action comes up (Sabiiti, (2011).

Most of the larger series of records in the National Archives, for example, were accessioned primarily for the information they contain relating to other matters than the action of the Government itself. Nyamungu, S. (2010). Among such series are the voluminous census schedules, military service records, pension files, passenger lists, land-entry papers, and various kinds of case files. In most instances such series shed light on the activity of Government agencies, but so little in proportion to their bulk that this is not an important factor in their selection for preservation; it is presumed that other records show the activity of the agencies more effectively.

Creating records contribute to greater business efficiency, build corporate memory by embedding knowledge in an organization support improved productivity because they enable easy access to shared information needed to make the right decisions at the right time and help to document the rights and entitlements of individuals and organizations (Sekaran, (2003). 
Creating records play a critical role in the process of policy formulation. Record is fundamental to public administration and bureaucracy generally. Records are central to public administration and bureaucracy because they "provide a reliable, legally verifiable source of evidence of decisions and actions" (World Bank, International Records Management Trust, \& Information Solutions (Schiavo-Campo, S. (2000),

\section{The influence of records maintenance and preservation on procurement performance}

Records maintenance and preservation involves physical storage and ensuring safety of records (Menkus, 1996). He considers archives as the organized records of governments, organizations, groups of people and individuals, whatever their date, form and material appearance, which are no longer needed to conduct current businesses but are preserved either as evidence of origins, structure, functions and activities or because of the information they contain. Another scholar, Evans (1988).

Preservation refers to the implementation of strategies that enhance and prolong the useable life of records and archives. These guidelines overwhelmingly refer to records, as responsibility for the care of archives is vested in the University Archives. Standards are necessary to ensure that fragile records and archives continue to be accessible for as long as they are required (Uduigwome 2016).

Responsibility for the records maintenance and preservation of records is vested in the creating office during the active and semi-active phases of the records life-cycle. Offices then are charged with ensuring accessibility in the short and medium terms. However, where it is evident that records will be required as archives, and to assist the University Archives in long-term preservation, standards in the storage and handling of records should refer to the long rather than short or medium terms. It is in the interests of all units of the University to work together to ensure the protection of its corporate memory and cultural heritage (Diamond, Susan. Z. 2017).

Records maintenance and preservation is a crucial element in the whole operation of a records programme. The aim of archival preservation is to prolong the usable life of useful research information in two ways. First, preventive preservation seeks to reduce risks of damage and to slow down the rate of deterioration. This aim is usually accomplished by selecting good quality materials and by providing suitable storage environments and safe handling procedures. Secondly, prescriptive preservation is a means of identifying and treating or copying damaged materials to restore useful access to the information. The information presented in this module can be used in government, corporate, organizational or personal settings. Many examples, including the fictitious 'Erewhon National Archives', are based on government situations, but the concepts illustrated should be easily applied to non-government archival institutions, local or regional government offices or private corporations or associations (International Records Management Trust (IRMT). (2009).

A variety of methods exist to protect records physically and ensure their stability and security. Environmental controls, the use of quality storage containers and good handling practices will help extend the life of archival materials. Some of the preservation measures discussed in this module are easily undertaken; others are more expensive or time consuming. Some require little training, while others should be done only under the supervision or with the assistance of a trained conservator. Naturally, the steps available to protect and preserve records and archives will vary depending on the availability of resources in different institutions (ISO 15489-1:2001.). 
This module discusses the physical preservation issues related to the protection of records and archives. The subject of preservation can be highly technical, and most trained conservators have a background in the science of chemistry. It is important to remember that remedial item-by-item conservation is an expensive service, requiring the participation of skilled and trained conservation specialists. Staff responsible for preservation should obtain professional qualifications and specialist training, a fact to be considered when planning for staff needs. Conservation and reprographic staff must be given parallel recognition with archives staff, since their duties and responsibilities are equally important (Parker, Elizabeth. 2016)

Preserving Records outlines the key concepts involved with the physical preservation and protection of records and archives, particularly those materials housed in archival repositories. The module discusses the importance of environmental protection and high-quality storage and handling practices. It examines the reasons for the degradation of archival materials and discusses methods to slow or stop deterioration. Queensland State Archives. (2010). The module also reviews the role of reprography in preservation management and discusses the importance of security in protecting records and archives.

On the other hand, described archives as having constituted one of the world's primary sources of information that grew uniquely out of the activities of organizations, institutions, families and individuals. Archives according to him are "records of an entity that have been selected for preservation because they possess enduring value". In the same perspective, The National Records and Archives Act (2001) defines archives as records of enduring value selected for permanent preservation. In this study, records maintenance and preservation has been categorized as backup, shelving, filling and archiving.

Findings by Obura (2011) indicate that effective records maintenance enhances procurement performance. This means that good record-keeping practices reduce vulnerability to legal challenge or financial loss and promote efficiency in terms of human and space resources through greater coordination of information use, maintenance and control. The Kenya Public Procurement Oversight Authority (2008) observes that unorganized and poorly managed records lead to inability to access information needed to support policy formulation, implementation and delivery of programs and services. It further highlights that failure to effectively maintain procurement records means that: decisions are taken on ad hoc basis without the benefit of records; fraud cannot be proven; and meaningful reporting and audits cannot be carried out.

In the same perspective, Duranti (2010) indicates that disorganized records mean reviewers and auditors take an excessive amount of time to locate needed records, which affects procurement performance. Procurement records are critical in promoting the principles of transparency and accountability, and weaknesses in this area are more likely to have implications for the efficiency and effectiveness of the public procurement system (Sabiiti et al., 2011). Therefore, it is presumed that records maintenance and preservation have a significant influence on procurement performance.

\section{The influence of records access and use on procurement performance}

The international standard for records management (ISO 15489-1: 2001) stipulates access as the right opportunity, means of findings, using or retrieving information. In this particular study, 
records access and use entails use, retrieval and dissemination. Diamond (1995) argues that once the records have been transferred to the archives, they need to be processed, conserved and made accessible as source of information or evidence. A well-managed procurement records management system will enable the physical and logical control of records and prevent unauthorized access, tampering, loss, misplacement or destruction of documents (Mnjama and Wamukoya, 2004). According to Duranti (2010), there can be no significant procurement systems without addressing record-keeping practices. Besides being a compliance measure, records are essential for accountability and effective performance.

Similarly, Obura (2011) contends that procuring bodies need to keep records of their decisions, activities and transactions to meet the demands of corporate accountability and compliance with procurement law, regulations and policies. In addition, Akporhonor and Iwhiwhu (2007) further indicate that, description and arrangements in archival context not only ensure proper organization of the records but also facilitate quick and easy access to the records when required. This shows that effective records access and use enhances procurement performance and is essential for ensuring transparency and probity in procurement and financial management.

Therefore, sound information and records management strengthen procurement best practices, as records are important for accountability and are a powerful deterrent against procurement and financial malpractices. Weak records management practices mean officials cannot be held accountable for their actions. Hence in this study, it is anticipated that records access and use have a significant influence on procurement performance.

The passage of the Access to Information Act made Uganda the first country in the East African Community enacts an FOI law. The Act sets out the structure for delivering Access to Information. It requires the information officer in each public body to prepare an information manual, including a description of the body and its functions, formal and informal procedures for facilitating a request for access, a description of the categories of records available without submitting a request and remedies available in case of a failure to act by the body. Shepherd, 2003. The Act requires the information officers to take all reasonable steps to find the record and to give a full account of all steps taken to determine whether the record exists, including all communications with every person who conducted the search on behalf of the information officer.

Access to Information is moving higher onto the national development agenda as Uganda prepares to host the pan-African NGO Africa Freedom of Information Centre at the Third Global Gathering of the Access to Information Initiative in October 2011. The Initiative is the world's largest network of civil society organizations and works to ensure that citizens have the right and the ability to influence decisions that affect them. The meeting, which will mark the Network's tenth anniversary, will be the first time that the event has been held in Africa. Over 125 participants from 37 countries are expected to attend. The Kampala Global Gathering will be organized around the theme: Access Rights, Poverty and Environmental Democracy Worldwide. The overall goal of the gathering is to formulate and adopt a forward-looking Global Plan of Action to accelerate the implementation of access rights as a strategy for achieving greater democracy and environmental sustainability at the national level. The meeting provides an opportunity to examine the issues from an African perspective. 
As the issue of Access to Information is widely publicized, for instance through country-wide training of trainers offered by the Human Rights Network for Journalists-Uganda, the issue of management of government records will need to be addressed. If not addressed, poor record keeping will present a significant impediment to Access to Information. Visits to government registries revealed large backlogs of paper records, stored wherever space could be found and managed by under-qualified staff. The paper records were not well organised and retention requirements had not been applied so that large volumes of inactive records occupied valuable office space World Bank, International Records Management Trust, \& Information Solutions Group. (2000).

\section{Conclusion}

Records management in government apparatus and public administration departments like KCCA, is always a paramount aspect that should not be undermined.in administration, management of records saves space by flashing out inactive records from crowding offices where space is at a premium good required. this is done through sending un used data to storage, timely destruction of records that are no longer needed, ensuring that records are well organized and maintained. This will create room for receiving new information and improve file management system used by administration. Proper data management in government departments encourages good governance practices by simplifying for office managers reach desired information at the time of search for files. This vice of proper data management gives chance to effective monitoring of government agendas which enhances smooth administration and management gap close. When making public sector planning the cycle is driven by data. Record management will close that gap that always has affected KCCA were contracts of civil servants were held missing, agreements signed and bids. Such vice, shall ensure sustainability in administration of procurement and logistic data and records for proper accountability and drive to reach new public management style. 


\section{REFERENCES}

Akporhonor, B.A. and Iwhiwhu, E.B. (2007), The Management of Staff Records at Delta StateAmin, M.E. (2005), Social Science Research, Makerere University Printery, Kampala.

Basheka, B.C. (2008), "Procurement planning and accountability of local government procurement systems in developing countries: evidence from Uganda", Journal of Public Procurement, Vol. 8 No. 3, pp. 135-144.

Chachage, B. and Ngulube, P. (2006), "Management of business records in Tanzania: an exploratory case study of selected companies", A Journal of Information Management, Vol. 8 No. 3, pp. 379-406.

Chief Information Officer (2007), "Electronic records management software applications design criteria standard", United States Department of Defense Standard 5015.02 (DoD Std 5012.02).

clients", Consultants and Contractors Construction Innovation, Vol. 11 No. 3, pp. 305-320.

Damulira, S.E. (2013), "Procurement and disposal audit report of ministry of health for the financial year 2012/2013”, 20Health\%20f (accessed 16 March 2016).

Diamond, S.Z. (1995), Record Management: A Practical Approach, 3rd ed., Amazon, New York, NY.

Diamond, Susan. Z. 2017. Records management: a practical approach/guide: policies practices resources technologies. 3rd (ed). New York: Amacom.

Duranti, L. (2010), "Concepts and principles for the management of electronic records, or records management theory is archival diplomatics", Records Management Journal, Vol. 20 No.

1, pp. 78-95.

Evans, B.F. (1988), Managing Archives and Archival Institutions, in James, B.G. (Ed.), Mansell Publishing, London.

ISO 15489-1:2001. Information and documentation records management part 1: general International Standards Organization.

KCCA Report (2013), Post Procurement Review Reports of the Agricultural Extension Project.

Kenya Public Procurement Oversight Authority (2008), "Procurement records management procedures manual", available at:

Lam, P.T.I. and Wong, W.H. (2011), “A comparative study of build-ability perspectives between

Langemo, M. (2002), Winning Strategies for Successful Records Management Programmes, Information Requirements Clearinghouse, Denver. 
Mahapatro, B.B. (2010), Procurement and Supply Chain Management, New Age Publishers, New Delhi.

Marutha, N.S. and Ngulube, P. (2010), "Records management: a foundation for business success, compliance and accountability with special focus on the public sector", paper presented at the Records Keeping and Data Management Conference, Johannesburg.

Menkus, B. (1996), "Defining electronic records management", Records Management Quarterly, Vol. 30 No. 1, pp. 38-42.

Mnjama, N. and Wamukoya, J. (2004), "E-government and e-records management", paper presented at the SADC Workshop on E-government, Gaborone, 14-16 April.

Moullin, M. (2004), "Evaluating a health service taskforce", International Journal of Health Care Quality Assurance, Vol. 17 No. 5, pp. 135-144.

Mugenda, O.M. and Mugenda, A.G. (1999), Research Methods; Qualitative and Quantitative Approaches, ACTS Publishers, Nairobi.

Ngoepe, M.S. (2004), “Accountability, transparency and good governance: the national archives and records service of South Africa's role in helping government to better service delivery 